Original Article - Clinical Science

\title{
Paracentral acute middle maculopathy as a finding in patients with severe vision loss following phacoemulsification cataract surgery
}

Katarina Creese MD FEBO, ${ }^{1,2}$ Daini Ong MBBS(Hons), ${ }^{1,2}$ Sukhpal S Sandhu MD FRANZCO, ${ }^{1,2}$ David Ware FANZCA, ${ }^{3}$ C Alex Harper FRANZCO, ${ }^{1,2}$ Salmaan H Qureshi FRANZCO ${ }^{1,2}$ and Sanjeewa S Wickremasinghe DMedSc FRANZCO ${ }^{1,2}$

${ }^{1}$ Medical Retina Unit, The Royal Victorian Eye and Ear Hospital, Melbourne, Australia.

${ }^{2}$ Centre for Eye Research Australia, University of Melbourne, Melbourne, Australia.

${ }^{3}$ Department of Anaesthesia, The Royal Victorian Eye and Ear Hospital, Melbourne, Australia.

No conflicting relationship exists for any author.

Correspondence: Sanjeewa Wickremasinghe, The Royal Victorian Eye and Ear Hospital, 32 Gisborne Street, East Melbourne, Victoria 3002, Australia email: Sanj.Wickremsinghe@eyeandear.org.au

Short running title: PAMM following cataract surgery

Received 16 August 2016; accepted 28 February 2017

Conflict of interest: None

Funding sources: None

This is the author manuscript accepted for publication and has undergone full peer review but has not been through the copyediting, typesetting, pagination and proofreading process, which may lead to differences between this version and the Version of Record. Please cite this article as doi: 10.1111/ceo.12945

This article is protected by copyright. All rights reserved. 


\section{ABSTRACT}

I mportance: Paracentral acute middle maculopathy (PAMM) as diagnosed by spectral domain optical coherence tomography (SD-OCT) may be associated with "patch off" visual loss post cataract surgery.

Background: To report a case series of severe vision loss due to PAMM after cataract surgery

Design: Retrospective case series.

Participants: Cases from five surgical centres (public and private) in Victoria, Australia.

Methods: Retrospective analysis of cases with unexplained "patch-off" vision loss post cataract surgery. All patients in our cohort had PAMM and presumed diagnosis of central retinal artery occlusion or transient retinal artery occlusion.

Main Outcome Measures: A review of the patient's history focusing on preoperative ocular and systemic vascular risk factors, anaesthetic factors and operative factors.

Results: Ten cases were included. All patients had 6/72 Snellen visual acuity or worse noted on day one post surgery. Three patients had features of central retinal artery occlusion consisting of retinal pallor with a "cherry red" macula but absent relative afferent pupillary defect. Seven had no features of retinal pallor or attenuation of retinal arterioles. On SD-OCT, all eyes had evident PAMM. Six patients had a history of cardiovascular disease or blood dyscrasia.

Conclusions and Relevance: PAMM should be considered in patients with "patch off" visual loss and absence of other fundal signs. We hypothesise that spasm or transient occlusion of central retinal artery leads to arterial hypoperfusion with subsequent ischaemia or infarction of the retina. Underlying arterial disease may have led to pre-existing hypoperfusion that may have been further compromised by raised IOP during the procedure itself or via raised orbital pressure from the anaesthesia. 
Keywords: Paracentral acute middle maculopathy, retinal artery occlusion, cataract surgery

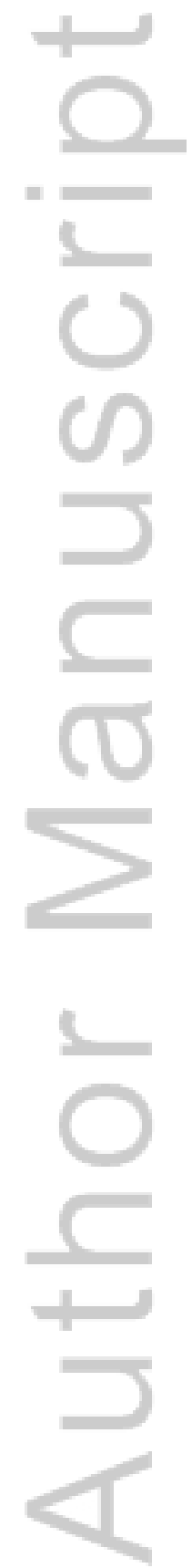

This article is protected by copyright. All rights reserved. 


\section{NTRODUCTION}

Cataract surgery is by far the most commonly performed operation by ophthalmologists. ${ }^{1}$ Over 29,000 cases were performed in Australia in $2014^{2}$ and 20 million worldwide. ${ }^{3}$ Local anaesthesia is a preferred method to achieve akinesia and analgesia in $74 \%$ of cataract surgery in Australia. ${ }^{4}$ Since cataract surgery generally has excellent outcomes, patients and surgeons have high expectations of the procedure. In contrast, when surgical complications with significant visual loss occur, patients are understandably distraught. Retinal artery occlusion after routine phacoemulsification is a seemingly rare complication, but has a devastating effect of immediate 'patch-off' poor acuity. Recently, PAMM has been described in patients with central visual loss. ${ }^{5}$ PAMM is an SD-OCT finding which in an acute stage appears as hyperreflective, band-like lesions in the middle retina, in the junction of the inner nuclear layer (INL) and outer plexiform layer (OPL) involving the entire INL with sparing of the outer retina. The SD-OCT location of the lesions suggests deep and intermediate capillary plexus ischemia associated with retinal vascular occlusive disease including retinal artery occlusion. Over time, these lesions progress to atrophy of the INL leaving the patients with permanent visual deficit and scotoma. PAMM is associated with multiple retinal vascular diseases ${ }^{6}$ and typically occurs in an older group of patients. ${ }^{5}$ Small cases series and several anecdotal case reports have been published describing central retinal artery occlusion (CRAO) or transient retinal artery occlusion (TRAO) following cataract surgery under local anaesthesia using retrobulbar, peribulbar or sub-Tenon's techniques. ${ }^{7-9}$ We present a series of cases of immediate 'patch-off' vision loss on day one post routine phacoemulsification cataract surgery. Our aim is to increase the awareness of this surgical complication, and to highlight the diagnostic feature of PAMM on OCT in suspected cases with minimal clinical findings. 


\section{METHODS}

Cases were reported from five surgical centres (public and private) in Victoria, Australia. Patients with unexpected poor visual acuity on the first day after uncomplicated cataract surgery in the absence of other pathology had an SD-OCT as part of their investigation. All patients had typical appearance of PAMM on SD-OCT imaging specifically hyper-reflectance of the middle macular layers. All participating surgeons provided clinical information with regards to details of management. A thorough systems and processes review of all cases was performed to identify pre-operative ocular and systemic vascular risk factors, anaesthetic factors (eg agents and volume, type of local anaesthetic), and operative factors (eg duration of surgery, the use of Honan's balloon).

\section{RESULTS}

Ten patients with dramatic visual loss following apparently uneventful phacoemulsification cataract surgery were reported from two public hospitals and three private practices between July 2014 and J uly 2016.

Table 1 describes the demographics and clinical features of the ten patients. There were four women and six men. The mean age $( \pm S D)$ of patients was $74.9 \pm 9.38$ (range 59-89) years. There was a history of controlled glaucoma in two patients, whilst five of the patients had a history of systemic hypertension managed with oral medication. Three patients had hypercholesterolaemia and two patients had a history of a blood disorder (thalassemia minor and autoimmune haemolytic anaemia respectively). The preoperative visual acuity ranged from $6 / 6$ to $3 / 60$.

All patients had regional blocks with six patients having sub-Tenon's and four a peribulbar approach. A mix of local anaesthetics was used for each case, with Lignocaine $2 \%$ used for all plus six had Ropivacaine $0.8 \%$ and four had Bupivacaine $0.4 \%$ 
and nine had the addition of hyaluronidase. The use of Honan's balloon was not recorded in any of the cases.

Surgery was performed by six registrars (under direct consultant supervision) and four consultant surgeons. Standard operating approach included clear corneal incision, the use of ProVisc ${ }^{\circledR}$ OVD (Alcon Laboratories, Inc), and capsulorhexis with either a pre-made cystotome needle or capsulorhexis forceps. All followed well established protocols for nucleus fragmentation (divide and conquer, primary chop) in phacoemulsification cataract surgery in designated operating theatres using Infiniti ${ }^{\circledR}$ (Alcon Laboratories, Inc, Fort Worth, Texas, USA), Centurion ${ }^{\circledR}$ (Alcon Laboratories, Inc, Fort Worth, Texas, USA), and Stellaris ${ }^{\circledR}$ (Bausch \& Lomb, Inc, Rochester, New York, USA) operating devices. The balanced salt solution for infusion had $0.5 \mathrm{ml}$ of $1: 1,000$ adrenaline, diluting it to $1: 1,000,000$. Six patients had nucleus removed using divide and conquer technique and four had primary chop with subsequent bimanual or co-axial aspiration of soft lens material. Intraocular implantation was in the posterior chamber, in the bag for all. Intraocular pressure (IOP) was not routinely measured at the conclusion of surgery but the aim was to leave the wounds sealed, unsutured, without excessive pressure. All patients had intracameral cephazolin $0.1 \mathrm{~mL}$ (Baxter Healthcare Corporation, Brunswick, Victoria, Australia) injection at the end of the procedure. Topical chloramphenicol, a single pad and a shield was placed over the eye. The mean duration ( \pm SD) of surgery was $20.7 \pm 7.5$ minutes, with no complications recorded at the time of surgery in any of the cases. At day one review, best-corrected recorded vision was universally poor, (3/36 to hand movements) with patients describing central visual loss with preserved peripheral vision. None of the patients had evidence of a relative afferent pupillary defect or anterior segment abnormality on clinical exam with a clear cornea was clear and centrally placed IOL, with no evident media opacities. IOP was within the normal range. Three patients had features of CRAO with retinal pallor and oedema but had no signs of an embolic event and absence of RAPD. Seven patients had no fundal 
abnormalities, specifically with no evidence of embolus or retinal pallor. SD-OCT revealed hyper-reflectivity in the paracentral middle layers in all cases. Two patients had fundus fluorescein angiogram, five had carotid doppler ultrasound, six had giant cell arteritis screen. None of our patients had clinical symptoms of giant cell arteritis and carotid duplex exam was normal in those tested.

Six of the ten reported cases were from one public hospital between J uly 2014 and J uly 2016, where a total number of 8,809 cataract operations were performed in that time period, suggesting a frequency of PAMM after cataract surgery of $0.068 \%$. The follow-up varied between 34 to 315 days in all patients in the series with no improvement in visual acuity during this period. At final follow up, all patients demonstrated thinning of the INL on SD-OCT.

\section{I llustrative case reports}

\section{Case 1}

A 71-year-old man with underwent an uneventful left cataract surgery under peribulbar anaesthesia. He had a previous history of primary open angle glaucoma that was controlled with prostaglandin eye drops. On day one follow up, he reported a dense central scotoma. He was comfortable and did not experience any pain in the postoperative period. Recorded visual acuity was hand motions with no improvement with pinhole or refraction. On clinical examination there was no corneal oedema and he had mild Descemet folds. His intraocular pressure was $24 \mathrm{mmHg}$ with the intraocular lens being placed centrally in the capsular bag. Central retinal pallor was noted on the fundus exam of the left eye (Figures $1 \mathrm{~A}$ and $1 \mathrm{~B}$ ). SD OCT showed significant retinal thickening with areas of hyper-reflectivity at the level of INL (Figures $1 \mathrm{C}$ and 1D). Systemic review was unremarkable including electrocardiogram and carotid doppler ultrasound. There were no sign or symptoms of giant cell arteritis, erythrocyte sedimentation rate and C-reactive protein were within normal limits. 


\section{Case 2}

A 60-year-old woman underwent a routine left cataract surgery under sub-Tenon's anaesthesia. On day one follow up, she reported reduced vision in the operated eye. Her recorded vision was 3/36, which improved to 6/36 with pinhole. On clinical examination there was no corneal oedema and she had mild Descemet folds. The patient did not experience any pain after the surgery. Her IOP was $14 \mathrm{mmHg}$ with the intraocular lens being placed centrally in the capsular bag. She was reviewed again four days later when subtle central retinal pallor was noted on the fundus exam of the operated eye (Figures 2A and 2B). SD-OCT confirmed hyper-reflectance in the parafoveal region in the middle macular layers (Figures $2 \mathrm{C}$ and 2D). Clinical examination and blood tests excluded evidence of giant cell arteritis, although she was found to have hypercholesterolaemia. Four weeks post surgery her vision remained poor at 3/60 and SD-OCT showed thinning of the temporal retina (Figures $2 \mathrm{E}$ and 2F).

\section{DISCUSSION}

When surgical complications with significant visual loss occur, patients and surgeons are understandably disappointed. In this series, patients underwent apparently uneventful phacoemulsification cataract surgery under routine local (sub-Tenon's and peribulbar) anaesthesia. All cases had visual deterioration from the first postoperative day when the patch was removed. The final visual acuity of all affected eyes is less than $6 / 60$ and this visual loss is irreversible. Only three eyes (30\%) had clinical features of CRAO with absence of RAPD. For others no evidence of abnormality was visible on fundal examination and the diagnosis was made with the observation of PAMM on SD-OCT. With respect to underlying medical problems, $60 \%$ had a medical history of vasculopathy and/or blood dyscrasias. 
In the series of cases from this public hospital we estimate the incidence of 1 in 1,468 cases $(0.068 \%)$, which is comparable to rates of endophthalmitis following cataract surgery ${ }^{10,11}$ This presentation serves as a report on an internal audit that had commenced to investigate this issue.

We hypothesize that the spasm or transient occlusion of central retinal artery leads to arterial hypo-perfusion with subsequent ischaemia or infarction of the retina with permanent visual loss. Thus the clinical presentations of CRAO and TRAO with associated PAMM can be viewed as a spectrum of the same disease entity. When the ocular perfusion pressure through the central retinal artery is substantially reduced for a prolonged period, the whole inner retina is affected and presents clinically as retinal pallor and cherry red spot typical of CRAO. If the reduction is more transient, the clinical appearance of CRAO may not be apparent since the ischaemia is more limited to the INL and adjacent layers as this region is the site of intermediate and deep capillary network, which has the lowest oxygen tension.

As for the mechanism of arterial hypo-perfusion we suspect that this may relate to spasm within or occlusion of the CRAO. TRAO and CRAO following cataract surgery has been reported previously but in small case series. In all reports, phacoemulsification cataract surgery has been carried under local anaesthesia. ${ }^{7-9}$ Anecdotally, no cases of CRAO post cataract surgery where topical anaesthesia is used, have been published. This may suggest that the effect may be related to mechanical compression. Swamy et al ${ }^{9}$ have suggested loculation of anaesthetic fluid (from sub-Tenon's or peribulbar anaesthetic) may become trapped within the periocular connective tissue causing focal mechanical compression of the central retinal artery. This compression may occur by movement of fluid to within the intraconal connective tissue or remain extraconal in the sub-Tenon space following peribulbar and sub-Tenon's anaesthesia respectively. ${ }^{12}$ Mechanical compression pre-operatively, but postanaesthetic, in the form of the Honan's balloon may facilitate this movement, as well as contribute to rise in intraocular pressure. 
The damaging vasoconstrictive effects of adrenaline in end-organ surgery are widely acknowledged. However, the literature suggests that a low dose of 1:100,000 used in digital surgery is thought to enhance the effects of local anaesthesia without complication, and suggest that higher doses of adrenaline and larger volumes of anaesthetic used lead to a damaging 'compartment syndrome' necrosis. ${ }^{13-15}$ The balanced salt solution for infusion during the cataract surgery of these cases had a much lower dose of 1:1,000,000. A dilution error is only possible to $1: 500,000$ as there is only $1 \mathrm{~mL}$ in a standard ampoule of 1:1,000 adrenaline. Another potential vasoconstrictive cause relates to the anaesthetic drugs themselves. There is evidence that Lignocaine and Bupivacaine have vasoconstrictive effects leading to a temporary reduction in the blood flow to the central retinal artery. ${ }^{16}$ Vasoconstrictive properties of Ropivacaine have been studied in vitro on arterioles of skin. ${ }^{17}$ The rise in orbital pressure associated with anaesthetic injection and/or rise in intraocular pressure with phacoemulsification may also contribute to diminished flow through the central retinal artery. Whilst for a Honan's balloon the external pressure is measurable by a gauge, where it is not used and digital pressure is applied to facilitate local anesthetic spread, there is uncertainty in the degree of pressure applied. With high infusion pressures, IOP has been measured up to $96 \mathrm{mmHg}$ at the time of cataract surgery ${ }^{18}$, which may also compromise central retinal artery blood flow for a period of time, but in all cases total duration of surgery was not prolonged (10-30 minutes). The accuracy of this duration is variable as it is a measure of time spent in theatre and not real surgical time. In addition, during surgery the pressure change is likely to be intermittent with fluctuations. High IOP at the end of surgery and a rise in pressure post-operatively (for example, retention of visco-elastic, overhydration of corneal wounds, extremely tight double padding) could be causative. In this series, there were no reports of pain from patients and first day clinical assessments did not suggest high IOP. Subclinical transient rises, however, cannot be excluded. 
In eyes with pre-existing low perfusion of the retinal circulation, (60\% of our cases had underlying vasculopathy) it is possible that these eyes were more susceptible to transient compression or spasm of the central retinal artery.

Drug toxicity from incorrect dilution and subsequent intraocular injection of high doses is a known cause of severe visual loss following cataract surgery. ${ }^{19}$ In this series intracameral cephazolin (Baxter Healthcare Corporation, Brunswick, Victoria, Australia) was used, not diluted in-house, and supplied from a manufacturer with differing batch number sources. Although several systemic medications can affect the retina, producing a variable picture on OCT ranging from loss of inner segment ellipsoid loss in paracentral location (hydroxychloroquine ${ }^{20}$ ), cystoid macular oedema (prostaglandin analogues ${ }^{21}$ ), ganglion cell layer oedema and retinal crystal deposition (anaesthetic agents, canthaxine ${ }^{22}$ ). To our knowledge PAMM has not been described as a finding in drug induced retinal toxicity and the cases we present in this series are not typical of drug toxicity as described in the literature. ${ }^{23-25}$ In this series of cases, there are many variable clinical factors. However, it is reasonable to conclude that the variable surgeons, aneasthetists, surgery locations, operating systems, equipment and drug batches lead to self-eradication as causative factors.

Potential limitations of the study are that $(5 / 10) 50 \%$ of our cohort did not have carotid doppler ultrasound examination at the time of presentation with visual loss. None of the patients however had visible retinal emboli and in three of the patients, there was no past history of ocular or systemic vascular problems. Two patients did have a history of prior stroke and had carotid disease excluded at the time of stroke diagnosis. Based on the clinical picture and the lack of medical history of the patients these investigations were not considered necessary at the time. Therefore, although we cannot conclusively exclude an embolic cause for the observed retinal artery obstruction, we feel that this is unlikely. 
The implications of this report therefore are multiple. For preoperative management, we recommend the risk of CRAO/TRAO to be included in the consent process for all patients having cataract surgery. In addition, if there are patients with a previous history of vascular problems, surgeons should consider cataract surgery under topical anaesthesia or assess arterial perfusion pressure through digital pressure to assess for pre-existing low perfusion prior to local anaesthesia. For local anaesthesia, general measures to reduce the risk of CRAO should include limiting the volume of the anaesthesia used and restricting injection against resistance. For susceptible and identified cases, mechanical devices such as the Honan's balloon should be used with caution. Intra-operatively, the management should include avoidance of episodic high ocular tension, complete removal of visco-elastic agents, an arbitrary final pressure check with avoidance of over-hydrating the wound and gentle single padding.

In conclusion, we hypothesise that in this case series, interruption affecting the inner retinal blood supply leads to arterial hypoperfusion with subsequent ischaemia or infarction of the retina. PAMM should be considered as a potential diagnosis in a case of "patch off' visual loss, especially where there are minimal or no apparent clinical signs. In such cases, the pathognomonic OCT signs of hyper-reflective middle layers may solve this diagnostic conundrum.

Acknowledgements: Assoc. prof. Diane Webster, Drs Tu Tran and Nishant Gupta for contribution of cases. 


\section{REFERENCES}

1. Admitted patient care 2013-2014: Australian hospital statistics [press release]. 2015. Available from: http://www.aihw.gov.au/publicationdetail/?id=60129550483.

2. AlHW. Cataract Surgery. Accessed Feb 2017. Available from: http://www.aihw.gov.au/eye-health/cataract-surgery/

3. - Review of Ophthalmology. Thoughts on Cataract Surgery:2015. Accessed Feb 2017. Available from: https://www.reviewofophthalmology.com/article/thoughts-on-cataract-surgery-2015.

4. Eichel R, Goldberg I. Anaesthesia techniques for cataract surgery: a survey of delegates to the Congress of the International Council of Ophthalmology, 2002. Clin Experiment Ophthalmol. 2005;33(5):469-72.

5. Rahimy E, Sarraf D. Paracentral acute middle maculopathy spectral-domain optical coherence tomography feature of deep capillary ischemia. Curr Opin Ophthalmol. 2014;25(3):207-12.

6. Chen X, Rahimy E, Sergott RC et al. Spectrum of Retinal Vascular Diseases Associated With Paracentral Acute Middle Maculopathy. American journal of ophthalmology. 2015;160(1):26-34.e1.

7. Feibel RA, Guyton DL. Transient central retinal artery occlusion after posterior sub-Tenon's anesthesia. J Cataract Refr Surg. 2003; 29(9):1821-4.

8. Vinerovsky A, Rath EZ, Rehany U, Rumelt S. Central retinal artery occlusion after peribulbar anesthesia. J Cataract Refr Surg. 2004;30(4):913-5.

9. Swamy BN, Merani R, Hunyor A. Central retinal artery occlusion after phacoemulsification. Retinal Cases and Brief Reports. 2010;4(3):281-3.

10. Barry P, Seal DV, Gettinby G et al. ESCRS study of prophylaxis of postoperative endophthalmitis after cataract surgery: Preliminary report of principal results from a European multicenter study. J Cataract Refract Surg. 2006;32(3):407-10. 
11. Friling E, Lundstrom M, Stenevi U, Montan P. Six-year incidence of endophthalmitis after cataract surgery: Swedish national study. $J$ Cataract Refract Surg. 2013;39(1):15-21.

12. Yusuf IH, Fung THM, Wasik M, Patel CK. Transient retinal artery occlusion during phacoemulsification cataract surgery. Eye. 2014;28(11):1375-9.

13. Sonohata $M$, Nagamine $S$, Maeda $K$ et al. Subcutaneous single injection digital block with epinephrine. Anesthesiol Res Pract. 2012;2012:487650.

14 - Hlicki J. Safety of Epinephrine in Digital Nerve Blocks: A Literature Review. J Emerg Med. 2015;49(5): 799-809.

15. Prabhakar H, Rath S, Kalaivani M, Bhanderi N. Adrenaline with lidocaine for digital nerve blocks. Cochrane Database Syst Rev. 2015(3):CD010645.

16. Findl O, Dallinger S, Menapace $R$ et al. Effects of peribulbar anesthesia on ocular blood flow in patients undergoing cataract surgery. Am J Ophthalmol. 1999; 127(6): 645-9.

17. Timponi CF, Oliveira NE, Arruda RM, Meyrelles SS, Vasquez EC. Effects of the local anaesthetic ropivacaine on vascular reactivity in the mouse perfused mesenteric arteries. Basic Clin Pharmacol Toxicol. 2006;98(5):518-20.

18. Zhao Y, Li X, Tao A, Wang J, Lu F. Intraocular pressure and calculated diastolic ocular perfusion pressure during three simulated steps of phacoemulsification in vivo. Invest Ophthalmol Vis Sci. 2009;50(6):2927-31.

19. McDonald HR, Schatz H, Allen AW et al. Retinal toxicity secondary to intraocular gentamicin injection. Ophthalmology. $1986 \mathrm{~J} \mathrm{ul} \mathrm{31;93(7):871-7.}$

20. Melles RB, Marmor MF. The risk of toxic retinopathy in patients on long-term hydroxychloroquine therapy. JAMA Ophthalmol 2014;132(12):1453-60.

21. Miyake K, I baraki N. Prostaglandins and cystoid macular edema. Surv Ophthalmol 2002; 47 Suppl 1:S203-18.

22. Drenser K, Sarraf D, Jain A, Small KW. Crystalline retinopathies. Survey of Ophthalmology 2006;51(6):535-49. 
23. Delyfer MN, Rougier MB, Leoni S et al. Ocular toxicity after intracameral injection of very high doses of cefuroxime during cataract surgery. $J$ Cataract Refract Surg. 2011;37(2):271-8.

24. Ciftci S, Ciftci L, Dag U. Hemorrhagic retinal infarction due to inadvertent overdose of cefuroxime in cases of complicated cataract surgery: retrospective case series. Am J Ophthalmol. 2014; 157(2):421-5 e2.

25. Faure C, Perreira D, Audo I. Retinal toxicity after intracameral use of a standard dose of cefuroxime during cataract surgery. Doc Ophthalmol. 2015;130(1):5763. 


\section{FIGURE LEGENDS}

Figure 1: (A) Colour fundus photograph of the right unaffected eye. (B) colour fundus photo of the left eye three days after uncomplicated cataract surgery. (C) SD OCT of the right eye. (D) SD OCT of the left eye three days post cataract surgery. Note central retinal oedema and hyper reflectivity of the inner nuclear layer.

Figure 2: (A) Colour fundus photograph of the non-operated right eye. (B) colour fundus photograph of the left eye four days after an uncomplicated cataract surgery. (C) SD-OCT of the right eye. (D) SD-OCT of the left eye four days after cataract surgery, note hyper reflective changes of the inner nuclear layer. $(E)+(F)$ SD-OCT of the right and left eye 32 days after the left cataract surgery. Note persisting hyperreflectivity of the middle macular layers associated with thinning of the temporal retina. 
TABLE

Table 1: Characteristics of cases with paracentral acute middle maculopathy related to cataract surgery under regional anaesthesia.

This article is protected by copyright. All rights reserved. 


\begin{tabular}{|c|c|c|c|c|c|c|c|c|c|c|c|c|}
\hline $\begin{array}{l}\text { Patient } \\
\text { number }\end{array}$ & $\begin{array}{l}\text { Age; } \\
\text { Gender }\end{array}$ & Eye & $\begin{array}{l}\text { VA before sur- } \\
\text { gery }\end{array}$ & $\begin{array}{l}\text { VA after } \\
\text { surgery }\end{array}$ & Glaucoma & $\begin{array}{l}\text { Anaesthetic used; } \\
\text { Total volume }\end{array}$ & $\begin{array}{l}\text { Type of anaes- } \\
\text { thesia }\end{array}$ & $\begin{array}{l}\text { Duration of } \\
\text { surgery }\end{array}$ & $\begin{array}{l}\text { IOP day } 1 \\
\text { after sur- } \\
\text { gery }\end{array}$ & GCA screen & Medical history & FFA \\
\hline 1 & $71, \mathrm{M}$ & $\mathrm{R}$ & $3 / 60, \mathrm{ph} 6 / 9$ & CF & No & Lig 2\%+Rop 0.8\%+Hyal; $5 \mathrm{~mL}$ & Periconal & $30 \mathrm{~min}$ & Not available & NAD & Nil & Not performe \\
\hline 2 & $82, M$ & $\mathrm{R}$ & $\begin{array}{c}6 / 60, \text { ph } 6 / 12 \\
-4.0 /+0.75 \times 150 \\
6 / 6 \\
\end{array}$ & $\mathrm{CF}$ & No & Lig 2\%+Rop 0.8\%+Hyal; 4mL & Sub-Tenon's & $17 \mathrm{~min}$ & Not available & NAD & $\begin{array}{l}\text { AO stenosis, MV regurgita- } \\
\text { tion, renal artery infarct, } \\
\text { HTN, thalassaemia minor }\end{array}$ & $\begin{array}{l}\text { Normal transi } \\
\text { times }\end{array}$ \\
\hline 3 & $80, \mathrm{M}$ & $\mathrm{L}$ & $6 / 16$, ph 6/12 & $2 / 60$ & Yes & Lig 2\%+Rop 0.8\%+Hyal; $5 \mathrm{~mL}$ & Peribulbar & $10 \mathrm{~min}$ & $10 \mathrm{mmHg}$ & NAD & HTN & Not performes \\
\hline 4 & $83, \mathrm{~F}$ & L & $6 / 18$, ph 6/12 & $\mathrm{HM}$ & No & Lig 2\%+Bup 0.4\%+Hyal; 4mL & Sub-Tenon's & $35 \mathrm{~min}$ & Not available & $\begin{array}{c}\text { Results not } \\
\text { available }\end{array}$ & HTN & $\begin{array}{c}\text { Normal transi } \\
\text { times }\end{array}$ \\
\hline 5 & $59, \mathrm{~F}$ & L & $6 / 60$, ph $6 / 24$ & $\begin{array}{c}3 / 36, \\
\text { ph } 6 / 36\end{array}$ & No & Lig 2\%+Bup 0.4\%+Hyal; 4mL & Sub-Tenon's & $23 \min$ & $14 \mathrm{mmHg}$ & $\begin{array}{l}\text { Not per- } \\
\text { formed }\end{array}$ & Hypercholesterolemia & Not performec \\
\hline 6 & $71, \mathrm{M}$ & L & $6 / 12$ & CF & No & Lig 2\%+Rop 0.8\%; 4mL & Peribulbar & $12 \min$ & $20 \mathrm{mmHg}$ & $\begin{array}{l}\text { Not per- } \\
\text { formed }\end{array}$ & Nil & Not performes \\
\hline 7 & $82, F$ & L & $6 / 18$ & $\mathrm{CF}$ & No & Lig 2\%+Bup 0.4\%+Hyal; 4mL & Sub-Tenon's & $20 \mathrm{~min}$ & $7 \mathrm{mmHg}$ & $\begin{array}{c}\text { ESR 130, Hb } \\
\text { 85, WBC 3.3, } \\
\text { CRP 8 } \\
\end{array}$ & $\begin{array}{c}\text { Autoimmune haemolytic } \\
\text { anaemia, HTN, RA, hyper- } \\
\text { lipidaemia, stroke }\end{array}$ & Not performes \\
\hline 8 & $61, \mathrm{M}$ & $L$ & $\begin{array}{c}6 / 19, \\
-8.75 /-0.5 \times 45 \\
\end{array}$ & $\mathrm{HM}$ & No & Lig 2\%+Bup 0.4\%+Hyal; $4 \mathrm{~mL}$ & Sub-Tenon's & $15 \mathrm{~min}$ & $14 \mathrm{mmHg}$ & $\begin{array}{c}\text { Not per- } \\
\text { formed }\end{array}$ & Nil & NAD \\
\hline 9 & $71, \mathrm{M}$ & $\mathrm{L}$ & $\begin{array}{c}\text { 6/12, } \\
-7.0 /+0.5 \times 50\end{array}$ & $\mathrm{HM}$ & Yes & $\begin{array}{c}\text { Lig } 2 \%+\text { Rop } 0.8 \%+H y a l ; \\
\quad 3.5 \mathrm{~mL}\end{array}$ & Peribulbar & $20 \mathrm{~min}$ & $24 \mathrm{mmHg}$ & NAD & Nil & $\begin{array}{l}\text { Not performec } \\
\text { - declined by } \\
\text { the patient }\end{array}$ \\
\hline 10 & $89, F$ & L & $1 / 24$ & $\mathrm{HM}$ & No & Lig 2\%+Rop 0.8\%+Hyal; 6mL & Sub-Tenon's & $25 \mathrm{~min}$ & $10 \mathrm{mmHg}$ & NAD & $\begin{array}{c}\text { IHD, HTN, hypercholester- } \\
\text { olemia, AO stenosis-post } \\
\text { TAVI }\end{array}$ & Not performe \\
\hline
\end{tabular}

$\mathrm{VA}=$ visual acuity; $\mathrm{CF}=$ counting fingers; $\mathrm{HM}=$ hand movement; $\mathrm{ph}=$ pin hole; Lig = lignocaine; Rop = ropivacaine; Bup = bupivacaine; Hyal $=$ hyaluronidase; $\mathrm{IOP}=$ intraocular pressure; $\mathrm{NAD}=$ normal; $\mathrm{ESR}=$ erythrocyte sedimentation rate; $\mathrm{CRP}=\mathrm{C}$ reactive protein; $\mathrm{WBC}=$ white blood cells; $\mathrm{Hb}=$ haemoglobin; $\mathrm{AO}=$ aorta; $\mathrm{MV}=$ mitral valve; $\mathrm{HTN}=$ hypertension; $\mathrm{RA}=$ rheumatoid arthritis; $\mathrm{IHD}=$ ischaemic heart disease; $\mathrm{TAVI}=$ transcatheter aortic valve implantation

This article is protected by copyright. All rights reserved. 

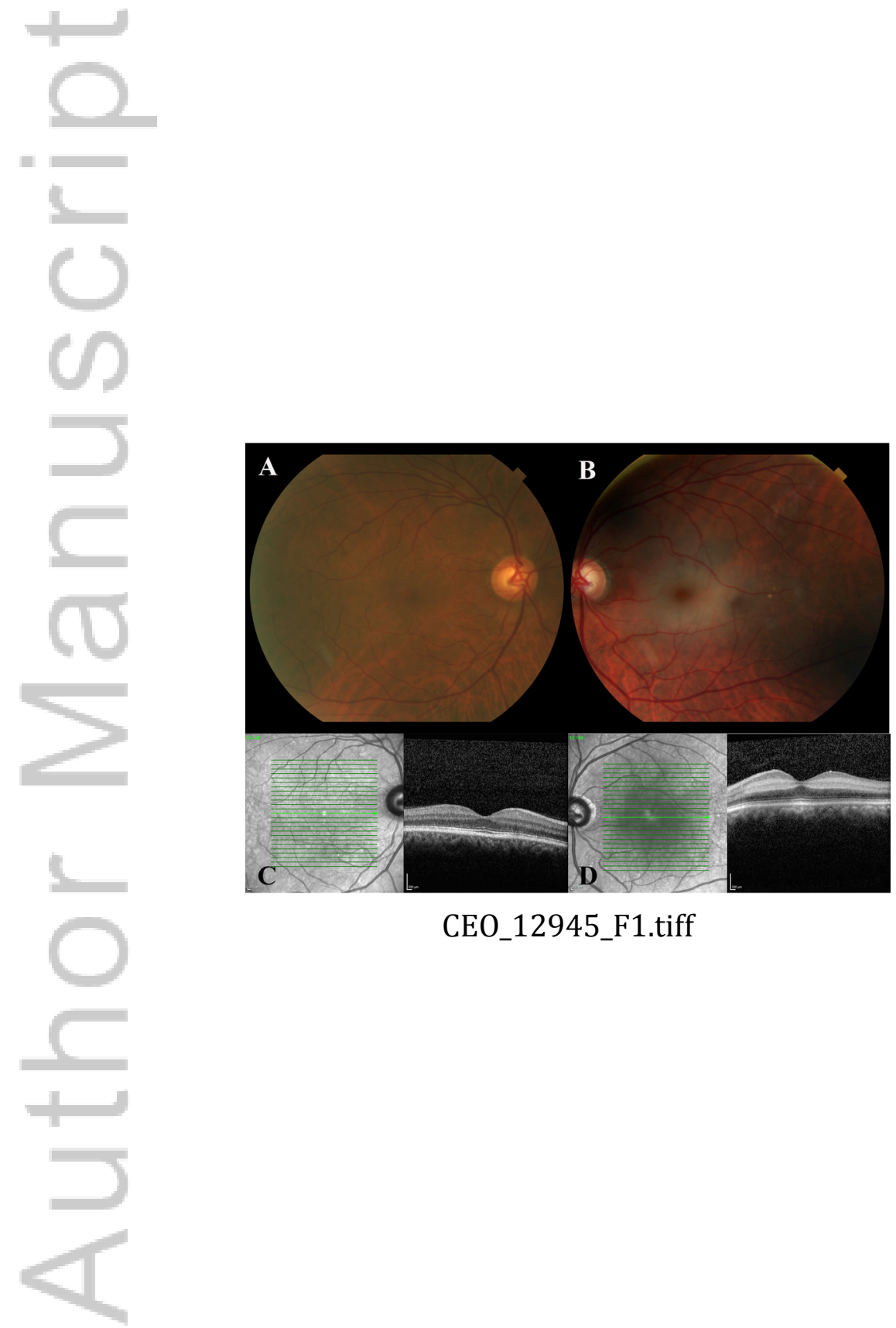

CEO_12945_F1.tiff

This article is protected by copyright. All rights reserved. 


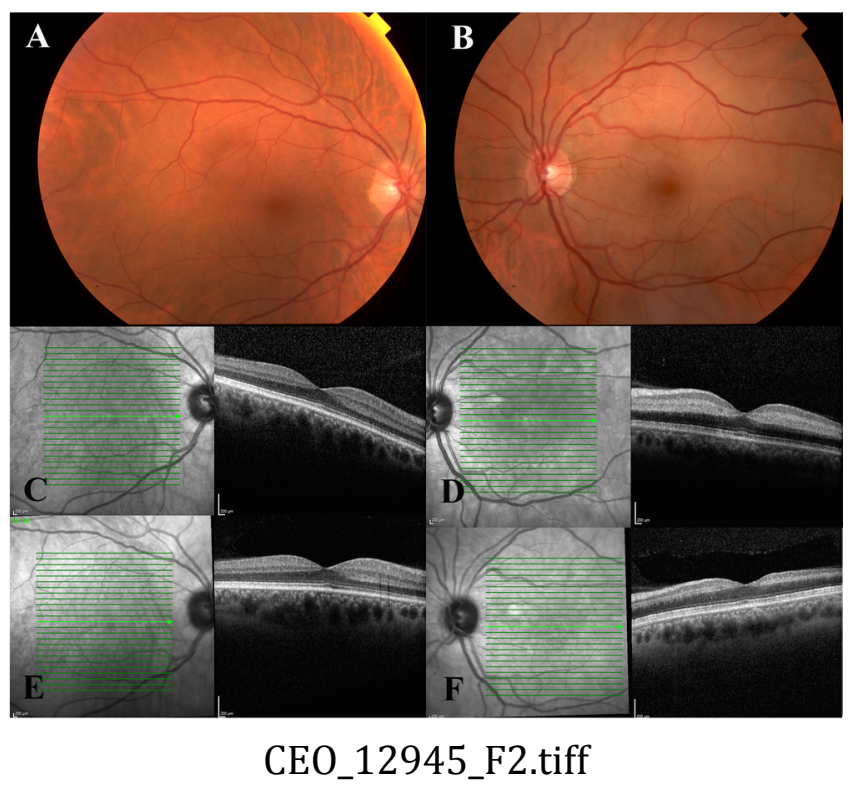

This article is protected by copyright. All rights reserved. 


\section{University Library}

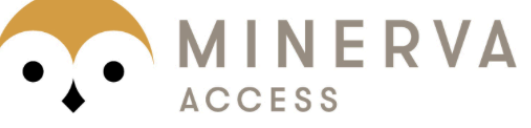

A gateway to Melbourne's research publications

Minerva Access is the Institutional Repository of The University of Melbourne

Author/s:

Creese, K;Ong, D;Sandhu, SS;Ware, D;Harper, CA;AI-Qureshi, SH;Wickremasinghe, SS

Title:

Paracentral acute middle maculopathy as a finding in patients with severe vision loss following phacoemulsification cataract surgery

Date:

2017-08-01

Citation:

Creese, K., Ong, D., Sandhu, S. S., Ware, D., Harper, C. A., Al-Qureshi, S. H. \& Wickremasinghe, S. S. (2017). Paracentral acute middle maculopathy as a finding in patients with severe vision loss following phacoemulsification cataract surgery. CLINICAL AND EXPERIMENTAL OPHTHALMOLOGY, 45 (6), pp.598-605. https://doi.org/10.1111/ ceo.12945.

Persistent Link:

http://hdl.handle.net/11343/292804 